\section{Innovative training for nurses in $\mathrm{SRH}$}

We read with great interest the article ${ }^{1}$ by Mehigan and Burnett in the July 2012 issue of this Journal about training for post-graduation nurses in this particular field of specialism and agree wholeheartedly with the authors about the deplorable lack of standardised training in the UK. It is important to equip nurses with knowledge and skills to provide competency in the delivery of safe and effective methods of contraception and the treatment of sexual health problems.

At Oxfordshire Contraception and Sexual Health Service (CASH) we have piloted our first training programme following the lead from the Reading model. We have used the e-SRH e-learning theory followed by the Course of 5 (C5) with clinical experience organised in clinical placements with dedicated mentors and course leader supervision.

A small cohort of nurses completed their training and evaluated the course positively. We are embarking on another course soon and hope that we can offer a more substantial validation in acknowledgement of all the trainees' hard work.

We look forward to an accreditation from the Faculty of Sexual \& Reproductive
Healthcare (FSRH) that addresses the disparity in training and assessment between doctors and nurses. A qualification for nurses similar to the FRSH Diploma (DFSRH) would be greatly appreciated.

Susan Hunt, RN, MSC

Clinical Nurse Specialist, Oxfordshire Contraception and Sexual Health Service, Alec Turnbull Centre, Cowley, Oxford, UK;

susanmhunt@hotmail.co.uk

\section{Doreen Onslow, RN}

Clinical Nurse Specialist, Oxfordshire Contraception and Sexual Health Service, Alec Turnbull Centre, Cowley, Oxford, UK;

doreen.onslow@oxfordhealth.co.uk

Competing interests None.

J Fam Plan Reprod Health Care 2012;38:273. doi:10.1136/jprhc-2012-100471

\section{Reference}

1 Mehigan S, Burnett J. An innovative training for nurses in sexual and reproductive health. J Fam Plann Reprod Health Care 2012;38:194-195. 